\title{
Recent developments in IFE safety and tritium research and considerations for future nuclear fusion facilities
}

\author{
Susana Reyes ${ }^{\mathrm{a}}$, Tom Anklam ${ }^{\mathrm{a}}$, Wayne Meier ${ }^{\mathrm{a}}$, Patrick Campbell ${ }^{\mathrm{a}}$,

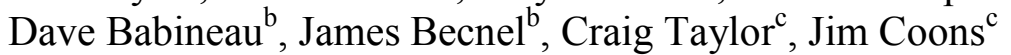 \\ ${ }^{a}$ Lawrence Livermore National Laboratory, Livermore, California \\ ${ }^{b}$ Savannah River National Laboratory, Aiken, South Carolina \\ ${ }^{c}$ Los Alamos National Laboratory, Los Alamos, New Mexico
}

\begin{abstract}
Over the past five years, the fusion energy group at Lawrence Livermore National Laboratory (LLNL) has made significant progress in the area of safety and tritium research for Inertial Fusion Energy (IFE). Focus has been driven towards the minimization of inventories, accident safety, development of safety guidelines and licensing considerations. Recent technology developments in tritium processing and target fill have had a major impact on reduction of tritium inventories in the facility. A safety advantage of inertial fusion energy using indirect-drive targets is that the structural materials surrounding the fusion reactions can be protected from target emissions by a low-pressure chamber fill gas, therefore eliminating plasma-material erosion as a source of activated dust production. An important inherent safety advantage of IFE when compared to other magnetic fusion energy (MFE) concepts that have been proposed to-date (including ITER), is that loss of plasma control events with the potential to damage the first wall, such as disruptions, are non-conceivable, therefore eliminating a number of potential accident initiators and radioactive in-vessel source term generation.

In this paper, we present an overview of the safety assessments performed to-date, comparing results to the US DOE Fusion Safety Standards guidelines and the recent lessons-learnt from ITER safety and licensing activities, and summarize our most recent thoughts on safety and tritium considerations for future nuclear fusion facilities.
\end{abstract}

Keywords: inertial fusion energy, magnetic fusion energy, safety, tritium, lithium, fusion nuclear science.

\section{Introduction}

Research on inertial fusion energy (IFE) started over 50 years ago, shortly after the invention of the laser in 1960. At that time, several scientists from Lawrence Livermore National Laboratory (LLNL) used early fusion design codes to study the possibility of using powerful laser pulses to compress and ignite a small quantity of deuterium-tritium (DT) fuel to the point of achieving self-sustaining fusion burn to create a net source of energy. Consistently around the world, investment in inertial confinement fusion (ICF) has focused on the study of optimized driver architectures (lasers, heavy ions, or pulsed power) and fuel illumination approaches (direct or indirect). The U.S. has made substantial investments in the field, culminating in the construction and operation of the National Ignition Facility (NIF) [1] at LLNL. Although NIF's primary mission is to provide important data for the Stockpile Stewardship program, an important goal is to achieve ignition and energetic gain in the laboratory, which will open up new frontiers in fundamental high-energydensity science and ultimately demonstrate the scientific feasibility of IFE [2].
In 2013, motivated by scientific and technological progress in international ICF programs together with the ongoing experiments being carried out at the NIF, the U.S. National Research Council completed a study on the Prospects for Inertial Confinement Fusion (ICF) Energy Systems [3] that assessed the status of domestic research in this field, identifying the scientific and engineering challenges associated with developing IFE as a potential future energy source. The outcome of this assessment indicated that the potential benefits of inertial confinement fusion energy provide a compelling rationale for establishing IFE R\&D as part of the longterm U.S. energy R\&D portfolio, and identified NIF as a major program element going forward in the assessment of the feasibility of IFE.

As contribution to the National Research Council study, researchers in LLNL completed an internal assessment of the research and development (R\&D) roadmap leading to an IFE demonstration plant based on laser driven inertial fusion, using a similar technological approach as the experiments pursued in the NIF $[4,5]$. Such assessment used a fully comprehensive systems engineering approach to identify at a conceptual level, the roadmap towards the delivery of a laser inertial

author's email: reyes20@llnl.gov 
fusion energy demonstration facility, integrating the activities required to progress from ignition on the NIF to a fully operational power plant. This included the staged approach to technology demonstration and implementation, facilitization of the vendor base, progression through the licensing framework, and facility design, construction and commissioning. The study pointed at some critical R\&D areas for the delivery of the IFE plant, which included all aspects of tritium breeding, processing and control, in addition to the development of a sound safety basis and the ability to license the facility. As a consequence, a series of tritium research and safety $R \& D$ activities emerged from this activity under the leadership of the LLNL team, and in collaboration with domestic and international tritium and safety experts. The status, future directions and possible impact from such activities upon other fusion concepts will be described next.

\section{Overview of the IFE facility}

\subsection{General description}

A conceptual laser IFE plant can be considered as four separable systems: (i) a laser driver to convert electricity into light, (ii) a fusion system to convert light into a hot working fluid, via the transport of neutrons, (iii) a balance of plant to convert heat into electricity, and (iv) a DT fuel cycle. Such subsystems have been described in detail in $[4,6]$.

As part of our internal IFE study, a series of requirements were developed in close consultation with the electric utility industry, a wide range of vendors, licensing experts, environmental groups, and a broad technical partnership. A key design characteristic adopted from the early stages of this activity is a highly modular design approach, allowing off-site factory manufacture of the principal sub-systems, and enabling a simplified operations and maintenance model consistent with conventional plant requirements.

The adoption of this type of modular architecture for specialized equipment has been tested previously in the "line replaceable unit" (LRU) approach successfully used on the NIF. This modularity approach together with the separability of the plant sub-systems, eliminates the need for development of advanced structural materials typical in previous MFE concepts, and facilitates the segmentation and segregation on hazards in the facility, including radiological hazards. Plant design criteria (including maintainability and availability) have been identified [5] to help establish objectives and assess IFE performance in comparison to alternative energy sources. Economic measures and the requirements for timely delivery are detailed in [7].

\subsection{Hazards assessment}

The main operating risks in a fusion nuclear facility relate to the presence of radioactive materials (tritium and activation products) that could conceivably be released to the environment following an accident. The hazards are primarily managed by the implementation of the main safety principles: as low as reasonably achievable (ALARA) and defense in depth. In this way, existing hazards are identified and maintained ALARA, and a confinement strategy is implemented based on multiple barriers to provide an appropriate level of protection, according to the level of risk. A particular hazard that must be considered in our IFE plant design is that associated to the use of liquid lithium as the blanket material. Lithium's well-known chemical reactivity could present a challenge for the confinement strategy just described above and therefore must be appropriately managed.

\subsubsection{Tritium}

The IFE fuel cycle has certain unique characteristics, like the use of only $1 \mathrm{mg}$ of tritium per fusion target, the limited plasma-wall interaction due to chamber gas protection scheme, and a high expected burn-up fraction $(\sim 30 \%)[6,8]$, which should be considered in the design of tritium processing systems. These intrinsic features are expected to allow for limited inventories inside the vacuum vessel and throughout the facility and simplify reprocessing requirements when compared to what has been traditionally proposed for MFE (see Table 1 for example typical parameters presented in literature).

Table 1. Example MFE/IFE fuel cycle parameters [4,9].

\begin{tabular}{|c|c|c|c|c|}
\hline & ITER & $\begin{array}{c}\text { MFE } \\
\text { DEMO }\end{array}$ & $\begin{array}{c}\text { IFE DEMO } \\
\left(1.2 \mathrm{GW}_{\text {th }}\right)\end{array}$ & $\begin{array}{c}\text { IFE Full } \\
\left(2.2 \mathrm{GW}_{\text {th }}\right)\end{array}$ \\
\hline $\begin{array}{c}\text { Fusion power } \\
(\mathrm{MW})\end{array}$ & 500 & 2700 & 1200 & 2200 \\
\hline $\begin{array}{c}\text { Fueling rate } \\
(\mathrm{kg} / \mathrm{hr})\end{array}$ & 1.1 & 1 & 0.03 & 0.06 \\
\hline $\begin{array}{c}\text { Burn fraction } \\
\text { T consumption } \\
\text { (g/day) }\end{array}$ & 0.003 & 0.02 & 0.23 & 0.27 \\
\hline $\begin{array}{c}\text { T recovery } \\
\text { (g/day) }\end{array}$ & 25257 & 20188 & 566 & 966 \\
\hline $\begin{array}{c}\text { T breeding } \\
\text { (g/day) }\end{array}$ & $<0.4$ & 450 & 203 & 439 \\
\hline Regarding & 76 & 169 & 960 \\
\hline
\end{tabular}

Regarding tritium inventories, a pre-conceptual level design of the complete IFE fuel cycle was completed using common tritium processing technologies available today, and presented in [10]. Detail on the functional requirements and technology selection for each of the fuel cycle sub-systems has been described in $[8,10]$. The initially proposed IFE fuel cycle concept was iterated upon by considering a series of design optimizations achievable with a moderate R\&D effort [10] that could allow for substantial inventory reduction compared with traditional technologies. For this purpose, a chemical flowsheet was designed to predict steady state tritium inventories using the Aspen simulation platform [11]. The IFE fuel cycle flowsheet was designed to support estimating the effects of design modifications upon fuel cycle inventories, and predicting the impact of alternate technologies. Simple models of process operations within each subsystem (e.g., diffusers, oxidizers, molecular sieve beds, etc) were developed and plugged in/out of the flowsheet to allow for these iterations. 
Table 2. Pre-conceptual-level estimation of tritium inventories in the full (2.2 $\left.\mathrm{GW}_{\mathrm{th}}\right)$ commercial IFE facility, and initial assessment of most promising technologies for inventory minimization.

\begin{tabular}{|c|c|c|c|c|}
\hline Fuel cycle sub-system & $\begin{array}{c}\text { Initial inventory } \\
(\mathrm{g}-\mathrm{T})\end{array}$ & Initial technology assumption & Design alternative & $\begin{array}{c}\text { Inventory } \\
\text { reduction }(\mathrm{g}-\mathrm{T})\end{array}$ \\
\hline Chamber & 66 & $\begin{array}{c}\text { Average gas } \mathrm{T}, \mathrm{P} \text { for total } \\
\text { chamber volume, assumes CGH } \\
\text { processes } 10 \% \text { of chamber } \\
\text { exhaust for T recovery }\end{array}$ & $\begin{array}{l}\text { Use of CVCs to } \\
\text { process } 100 \% \\
\text { exhaust, needs } \\
\text { further analysis }\end{array}$ & \\
\hline Lithium blanket & 60 & $\begin{array}{c}\text { Assumed 0.1 wppm T } \\
\text { concentration based on molten } \\
\text { salt extraction [9] }\end{array}$ & & \\
\hline $\begin{array}{l}\text { Chamber Gas Handling } \\
\text { System }(\mathrm{CGH})\end{array}$ & 86 & $\begin{array}{c}\text { Exhaust is } 5 \% \text { of chamber vol; } \\
\text { plus one Xe separation column to } \\
\text { process } 10 \% \text { of exhaust }\end{array}$ & & \\
\hline $\begin{array}{l}\text { Light Isotope Purification } \\
\text { (LIP) }\end{array}$ & 4,802 & $\begin{array}{l}\text { Catalytic oxidation and mol. sieve } \\
\text { bed regeneration ( } 4 \text { days reg. } \\
\text { time, non-acceptable for IFE) }\end{array}$ & $\begin{array}{l}\text { Diffusers, PMRs } \\
\text { (option to combine } \\
\text { with DS and by- } \\
\text { pass LIP) }\end{array}$ & -4782 \\
\hline Isotope Separation (IS) & 563 & Current TCAP process & $\begin{array}{l}\text { Next generation } \\
\text { mini TCAP }\end{array}$ & -282 \\
\hline Detritiation Systems (DS) & 9 & $\begin{array}{c}\text { Three stages of ITER-sized } \\
\text { diffusers and PMRs }\end{array}$ & & \\
\hline DT storage (DTS) & 71 & Target fill lag storage $=1$ hour & & \\
\hline Target Fabrication (TF) & 104 & $2 \mathrm{hr}$ target holdup and $10 \mathrm{~min}$ lag & & \\
\hline Target Transport (TT) & 22 & 20 min target holdup & & \\
\hline Target Injection (TI) & 5 & 5 min target holdup & & \\
\hline $\begin{array}{l}\text { Total Facility Tritium } \\
\text { Inventory }\end{array}$ & $\sim 5,788$ & & & $\begin{array}{l}<1,000 \mathrm{~g}-\mathrm{T} \\
\text { achievable }\end{array}$ \\
\hline
\end{tabular}

It must be emphasized that the results presented here are based on pre-conceptual level design assumptions, and detailed models of process operations within each subsystem should be performed as the design matures. A summary of the initial evaluations of tritium inventories and technology assumptions by sub-system are shown in Table 2.

This assessment shows potential for large reductions in the plant tritium inventory by utilizing technologies that have been proven on an experimental scale or are already under development yet not fully commercialized, such as mini-TCAP [12], Palladium Membrane Reactors (PMRs) [13], and Cryogenic Viscous Compressors (CVCs) [14]. In particular, two systems show significant inventory reduction potential: Light Isotope Purification (LIP) and Isotope Separation (IS). The initial LIP design contained $83 \%$ of the total facility inventory, due to the long regeneration time of the molecular sieve (MS) beds based on an over-simplified nearly spherical tank with desorption controlled by band heating on the tank exterior. The regeneration time of the MS beds would be greatly improved by simply optimizing bed geometry and the regeneration methodology. Furthermore, an even more significant tritium inventory reduction would be realized if the MS beds in LIP could be replaced by diffusers (typically palladium-silver alloy membrane permeators). Diffusers take advantage of the fact that molecular hydrogen can rapidly diffuse through palladium alloy membranes while other compounds are completely excluded [13]. Diffusers do not include any significant quantity of condensed phases, allowing for a reduction of over $90 \%$ in the LIP major equipment inventory. The Thermal Cycling and Adsorption Process (TCAP) in IS holds $10 \%$ of the total tritium inventory. The conventional TCAP consists of a $\mathrm{Pd} / \mathrm{k}$ packed column and a plug flow reverser (PFR) column. Mini-TCAP replaces the PFR with an active column that provides the inverse isotopic effect of the palladium column, doubling the process throughput while producing a higher purity raffinate in addition to the high purity product [12]. Finally, another possible design improvement has been identified in the Chamber Gas Handling (CGH) system, which purifies the xenon chamber gas for recycle into the chamber and recovers the unspent fuel. This initially was accomplished by passing a portion of the chamber exhaust through a series of condensers to first separate out compounds lighter than xenon (like water vapor, carbon dioxide, and methane), and then condense xenon from hydrogen and helium. Due to the cost of compression and the uncertainty in condenser design, the pre-conceptual design only processed $10 \%$ of the exhaust stream for fuel recovery. Currently under development for other fusion applications, Cryogenic Viscous Compressors (CVC) are tritium-compatible, single stage condensers that could handle the entire IFE chamber gas exhaust flow [14]. Designed to condense molecular hydrogen from helium, CVCs could more readily handle the requirements for Xe purification and recycle and tritium recovery.

Future work will focus on additional optimization and design iteration, with the goal of advancing the design towards the conceptual stage. Trade-offs between 
the tritium plant subsystems need to be carefully analyzed, and the design improved and optimized along the ALARA principle for tritium inventories, and the implementation of the confinement approach.

\subsubsection{Activation products}

In a fusion nuclear facility, a second radiological hazard is that related to activated materials that exist as a consequence of the neutron irradiation of structures and fluids in the fusion operations area. In LLNL's IFE study, using a lithium blanket in a ferritic-martensitic steel chamber [4], the activation of the liquid breeder material is low compared to the contribution from the steel chamber structures which could be mobilized in case of a major accident (see relative low lithium activation in Figure 2). In order to estimate the material activation, the MCNP Monte Carlo neutron transport code [15] has been used to calculate neutron fluxes throughout the facility. Results on activation level and residual decay heat have been obtained using the ACAB code for over a total of 100 years after shut-down [16]. The chamber material is assumed to be a low-impurity version of HT-9 steel [17]. Oxidation-driven mobilization data from Idaho National Laboratory [18] has been used to estimate the amount of mobilized chamber material as a function of the temperature for each of the assessed accident scenarios. The activation of the xenon chamber fill gas and the argon inert gas that surrounds the heat transfer systems has also been calculated. These gases are assumed to be $100 \%$ mobile in case of any off-normal event, as will be presented in the accident analysis results section.

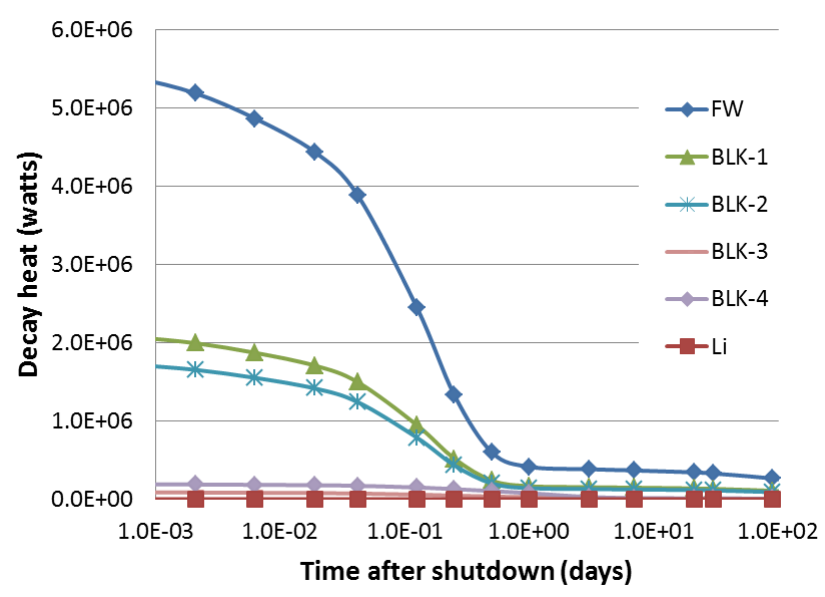

Fig. 1. Decay heat from chamber activation (first wall, blanket structures and liquid lithium), assuming 30 years of operation at $2210 \mathrm{MW}_{\text {fusion }}$, and FW lifetime of 1-yr.

As in the case of tritium, hazards management is based on minimization of inventories following the ALARA principle, and implementation of multiple confinement barriers to limit the possible spread of radioactivity to the environment. It is worth noting that the use of indirect-drive targets and a low-pressure chamber fill gas eliminates plasma-material erosion as a major source of activated dust production. In this sense, the lack of interaction of the fusion plasma with the chamber walls inherent to laser IFE is a safety advantage when compared to magnetic fusion energy concepts based on the tokamak approach (including ITER). Plasma events with potential impact to the first wall, such as disruptions, are not conceivable in the IFE approach, therefore eliminating a number of potential accident initiators and mobilizable activation products generation.

\subsubsection{Lithium hazards}

\subsubsection{Chemical reactivity hazards}

The safe handling of liquid lithium has been addressed in relation to the chemical reactivity of the material with air, water and other substances $[19,20]$. At the blanket temperatures here considered $\left(475-575^{\circ} \mathrm{C}\right)$ vigorous exothermic reactions of lithium with water and air could lead to confinement challenges, such as oxidation-driven mobilization of activated steel. In addition to the steel source term, potential spills could lead to the mobilization of the tritium content in the liquid lithium. Furthermore, hydrogen production from lithium reactions with water (see Equation 1), could present an additional explosion hazard during hypothetical lithium-water accidents.

$$
2 \mathrm{Li}(s)+2 \mathrm{H}_{2} \mathrm{O}(l) \rightarrow 2 \mathrm{LiOH}(a q)+\mathrm{H}_{2}(g)
$$

The primary strategy for controlling lithium's chemical reactivity hazards in the facility includes the following measures:

- Use of an inert cover gas (argon) around lithium heat transfer systems.

- No water present in the fusion operations area and protection against external flooding.

- Liners over all concrete surfaces potentially exposed to spilled lithium

- Low pressure lithium inventory and segmented design.

- Use of multiple containment methods to lithium release (e.g. dump tanks).

- Minimized tritium inventory in the lithium to avoid radioactivity release in the event of a spill.

Implementation of the multiple defense lines described above and of the ALARA principle for tritium inventories has been a key driver of the lithium blanket and heat transfer system design, as described next.

\subsubsection{Tritium breeding and extraction}

Assuming that lithium's chemical hazards are appropriately managed, it is recognized that liquid lithium offers many virtues fusion blanket cooling and breeding material: low density, high thermal capacity, good thermal conductivity, high potential to breed tritium due to its high neutron capture cross-section, and high affinity for hydrogen isotopes that minimizes tritium permeation. The low neutronic activation and low corrosion expected from the use of pure lithium also appear as safety advantages when compared with lithium salts or alloys. High hydrogen affinity, however, complicates tritium recovery while operational safety demands a low tritium inventory. The blanket tritium recovery system should be able to keep the tritium 
steady state inventory ALARA. Based on initial safety assessments, a reasonable design goal is to maintain the inventory under $\sim 100 \mathrm{~g}$. The total amount of liquid lithium in the facility is estimated to be $\sim 600$ tons, thus requiring a steady state concentration of tritium in liquid lithium of 0.1 wppm. Given the impact of the tritium recovery efficiency upon the safety and sustainability of the fuel cycle, we have conducted a detailed assessment of possible alternatives. Several options have been evaluated based on previous studies and available literature, including permeable windows [21-23], gettering process [24,25], cold trap [26-28], distillation [29-32], molten salt extraction [33-37], and combination of gettering and molten salt extraction [38]. Based on a pre-conceptual functional requirements analysis, the molten salt extraction method was selected as primary candidate due to its capability to achieve lower inventories, moderate energy requirements, low estimated capital cost and faster dynamic response. An important characteristic of the molten salt extraction method is being free from solid-state diffusion, a very slow process that may be impractical for large-scale separation. Instead, faster liquid phase diffusion is used, allowing to process lithium flow rates consistent with the desired recovery efficiency.

In the molten salt extraction approach (shown in Figure 2), the liquid lithium that contains tritium is first mixed with lithium halide salts in a centrifugal contactor/separator. Maroni et al. [33] demonstrated that the LiT moves preferentially from the liquid lithium to the salt when they are mixed. The salt is then circulated to an electrolyzer where the LiT is oxidized to form T2, which is swept from the salt phase by bubbling noble gas. The gas mixture is finally directed to a getter system that recovers the pure tritium and sent towards the tritium plant for further fuel manufacturing. The key steps of this process have demonstrated at laboratory scale $[33,34]$, with evidence of extraction feasibility down to $1 \mathrm{wppm}$ of tritium in the lithium, for fusion blanket applications. The initial conclusions also suggest that lower inventories can be achieved by simply scaling up the number of extraction units in the system; nevertheless more research is needed to verify this claim. Using correlations for processing flow rate estimations from available studies $[33,36]$ and conservative values for system performance (contactor efficiency of 0.4 and electrolyzer efficiency of 0.9 [36]), and assuming a commercial unit with a lithium throughput of 757 liters per minute $(200 \mathrm{gpm})$, we calculate a total of 9 contactors per loop required for the full commercial size (2.2 GWth) IFE plant (4 contactors in case of the 1.2 GWth IFE DEMO), followed by one electrolyzer unit and one getter per loop. This initial estimate seems to indicate that a relatively compact system with moderate power consumption could recover tritium at the needed rate to maintain the steady state inventory at the desired 0.1 wppm level. It must be noted that some extrapolations relative to the performance of the contactor, electrolyzer and getter for power plant scale processing will need to be verified, and an experimental
R\&D program should be initiated in order to advance the system design and reduce the technical uncertainties.

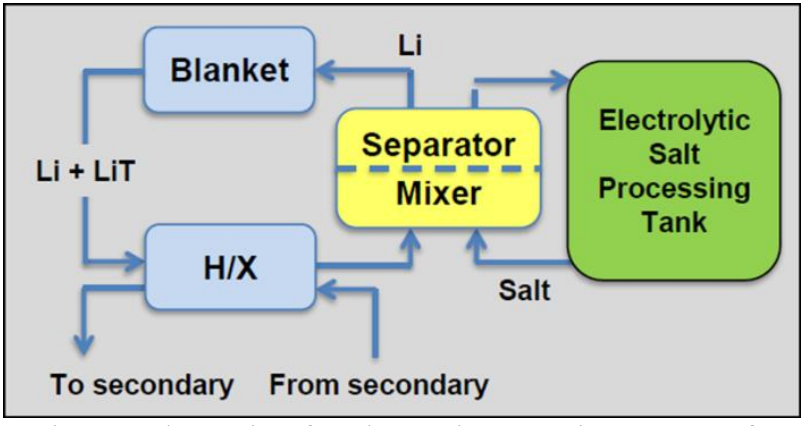

Fig. 2. Schematic of molten salt extraction process for tritium recovery from lithium.

\section{Analyses of accident scenarios}

A preliminary safety assessment for the IFE plant has been completed. The analyses of postulated events performed to date focus on scenarios that have been specified based on a deterministic selection process, taking into account the major inventories at risks and the potential release pathways. Two representative worstcase accidents are presented in this paper, which involve large lithium spills combined with loss of primary and secondary confinement and subsequent fire (i.e., invessel or ex-vessel loss of coolant combined with air ingress and fire). Although these are considered highly unlikely events, at this early stage of the design these analyses are used to explore the ultimate safety margin of the facility. As the design evolves, more realistic accident scenarios will be studied following a systematic approach for identification of design and beyond design basis events, as is the common practice for developing the safety basis of a fusion nuclear facility [39].

These accidents were simulated with a version of the thermal-hydraulics code MELCOR that has been modified for fusion applications, allowing for use of lithium as the working fluid [40]. A detailed description of the model and the thermal-hydraulics results has been documented in [41]. Figure 3 shows the temperature transient in the chamber structures in the case of invessel loss of coolant (assumes failure of all lithium pipes) with simultaneous air ingress and fire. The thermal histories of the chamber components have been used to define the activated steel oxidation-driven source term that will be treated as aerosols by the code MELCOR. Figure 4 gives the cumulative HT-9 aerosol generation as a function of time.

The simulation of tritium mobilization and transport uses a similar method. From initial MELCOR simulations of lithium spills followed by fire, one can infer the tritium mobilization rate for inventory that is present in the spilled lithium, as a function of the reaction rate. This tritium can also be then tracked in a subsequent MELCOR run, to simulate the ultimate release to the environment. According to the thermalhydraulics simulations, about $22 \%$ of the total lithium inventory in the plant will spill and react with air. 
Considering that the steady state concentration of tritium is $0.1 \mathrm{wppm}$, about $13.4 \mathrm{~g}$ - $\mathrm{T}$ are mobilized in these scenarios. Finally, the simulation also tracks the transport and final release to the environment of other activated gases around the fusion operations area like the xenon chamber fill gas, and the argon gas initially surrounding the lithium heat transfer systems.

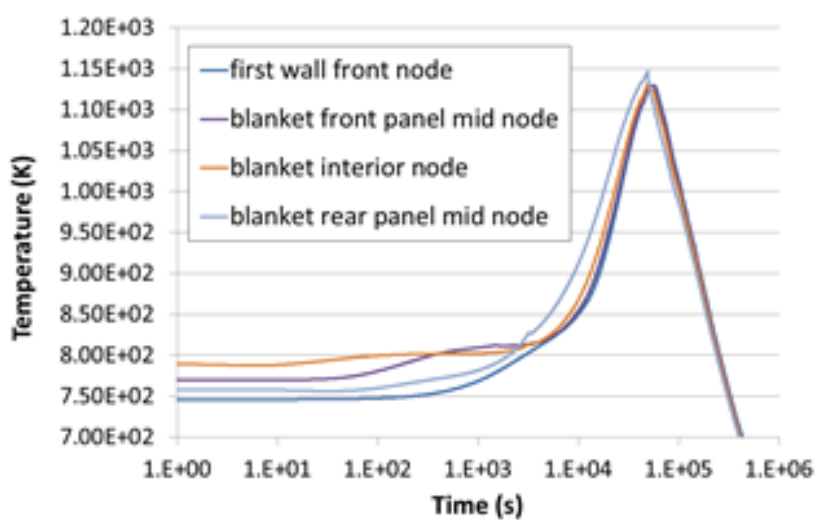

Fig. 3. Temperature transient in chamber structures in case of in-vessel loss of coolant and fire (IVF).

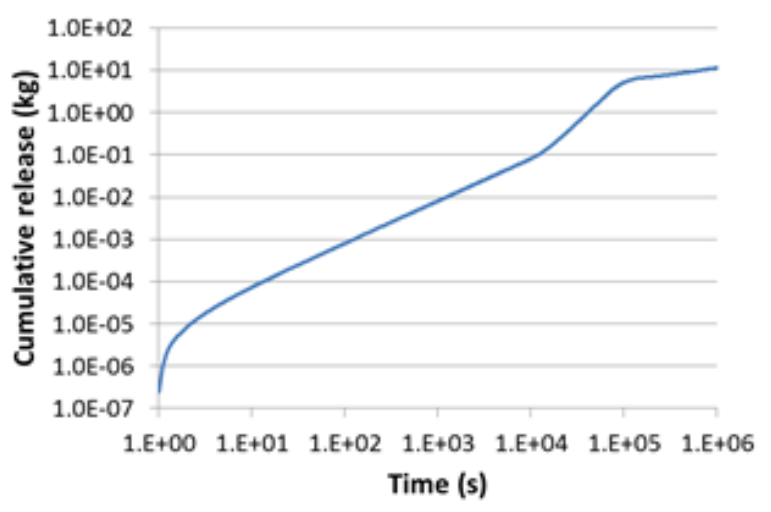

Fig. 4. Cumulative oxidation-driven mobilization of HT-9 steel during an IVF accident.

Table 3 shows a summary of the in-vessel and exvessel fire (IVF and EVF) accident simulation results. The four radioactive source terms described above (oxidized steel, tritium, xenon and argon) have been accounted for in these scenarios. This table shows the mobilized mass and the final release to the environment at 7 days after the beginning of the accident. Note that this is a very conservative assumption for the duration of the release; nevertheless it serves our initial purpose of exploring the safety limits of the facility.

We have used a set of calculated dose conversion factors (DCF) [42] to estimate accident doses based on the releases to the environment. The DCF library was generated for IFE-relevant isotopes to include radionuclides that were missing from traditional (fission) nuclear data libraries. Early doses were calculated using the code MACCS [43], and assuming a ground level release. Although it is out of the scope of this paper to provide detailed dose calculations given the early stage in the design, we have used typical values for the atmospheric dispersion conditions $(4.5 \mathrm{~m} / \mathrm{s}$ wind speed, Class D stability), so as for the site boundary $(1 \mathrm{~km})$. Initial results show that the non-evacuation limit (1 rem) [44] is achievable in all the assessed scenarios involving lithium spills and air ingress with subsequent lithium fire. Additional work needs to be done in the case of hypothetical scenarios involving lithium spills and water. Nevertheless, because of the additional hazards posed by potential hydrogen generation, it is strongly recommended that use of water is eliminated from the fusion operations area and that protection against external flooding is appropriately implemented.

\section{Safety and tritium considerations for future fusion nuclear science}

When considering the construction and operation of a future fusion nuclear science facility or a DEMO (either IFE or MFE), it is recognized that much work needs to be done in the safety and licensing area. The US DOE Fusion Safety Standards $[44,45]$, provide general safety requirements and guidance for fusion experimental facilities, such as the non-evacuation criteria used above. Nevertheless, these Standards were issued back in 1996 and must be brought up to date to ensure the congruency with current regulations, and with expanded current understanding of fusion safety challenges. Regarding the ITER precedent set by the French regulator [46], it is important to recognize that regulations developed for this first-of-a-kind tokamak in France may turn out to be overly conservative or simply inappropriate for practical application to next step fusion facilities. Potential key items that need to be examined/re-visited based on experience in ITER include: load cases, acceptance criteria, safety margins, materials qualification approaches and seismic, fire and explosion requirements [46].

Furthermore, future fusion power plant operations will present different safety characteristics compared to current pulsed fusion experimental facilities such as ITER. It is also clear that the safety features of future IFE and MFE facilities could differ significantly, not only in those aspects related to the behaviour of the plasma, but also in terms of amount of radioactive source term, available energy sources and potential initiating events. As an example, Table 4 gives a comparison of estimated accident source terms in various IFE facilities, compared to ITER.

Table 3. Summary of initial accident analysis results including initial radioactive source terms, mobilized materials during the accident, and final release to the environment assuming a transient duration of 7 days, for two accident scenarios (in-vessel lithium spill and consequent fire, and ex-vessel lithium spill and consequent fire). 


\begin{tabular}{|c|c|c|c|c|c|}
\hline Source term & Initial kg & $\begin{array}{c}\text { IVF } \\
\text { mobilized kg }\end{array}$ & $\mathrm{kg}^{\text {IVF released }}$ & $\mathrm{kg}^{\text {EVF mobilized }}$ & ${ }_{\mathrm{kg}}$ EVF released \\
\hline Steel & $2.75 \mathrm{E}+06$ & 13.6 & $2.64 \mathrm{E}-03$ & 9.36 & $2.53 \mathrm{E}-04$ \\
\hline Tritium & 0.067 & $1.34 \mathrm{E}-02$ & $1.08 \mathrm{E}-03$ & $1.34 \mathrm{E}-02$ & $1.43 \mathrm{E}-03$ \\
\hline Argon & $4.52 \mathrm{E}+02$ & $4.52 \mathrm{E}+02$ & 21.9 & $4.52 \mathrm{E}+02$ & 36.4 \\
\hline Xenon & $1.49 \mathrm{E}+03$ & $1.49 \mathrm{E}+03$ & 173 & $1.49 \mathrm{E}+03$ & 248 \\
\hline
\end{tabular}

Table 4. In-vessel radioactive source term for ITER and various IFE designs $[47,48]$.

\begin{tabular}{|c|c|c|c|c|}
\hline $\begin{array}{c}\text { Mobilizable } \\
\text { source term (kg) }\end{array}$ & ITER & HYLIFE-II & SOMBRERO & $\begin{array}{c}\text { IFE Full } \\
(2.2 \text { GWth })\end{array}$ \\
\hline In-vessel tritium & 1 & 0.14 & 1.17 & 0.06 \\
\hline $\begin{array}{c}\text { Mobilizable } \\
\text { activation products } \\
\text { (dust) }\end{array}$ & $\begin{array}{c}1000 \\
(\mathrm{~W})\end{array}$ & $\begin{array}{c}0.5 \\
(\mathrm{SS})\end{array}$ & $\begin{array}{c}50(\mathrm{C} / \mathrm{C} \\
\text { composite })\end{array}$ & $\begin{array}{c}13.6 \\
(\mathrm{HT}-9)\end{array}$ \\
\hline
\end{tabular}

Considering all of the above, it is clear that the licensing process for a commercial fusion facility will need careful detailed planning and that final requirements are unclear at this early stage. However, initial consultations with nuclear licensing experts indicate that fusion could in principle follow a nonprescriptive, risk-informed, performance-based approach to technical requirements, rather than the deterministic and technology-specific approach currently used for the light water reactor (LWR) fleet in the US. In the meantime, it is critical that the fusion community continue to develop and update safety rules in a prudent manner based on strong technical arguments that will in the future help the regulator make the most informed decisions possible.

\section{Conclusions}

The safety characteristics and at risk inventories in an IFE facility have been discussed. The primary nuclear hazard in a fusion facility is the potential exposure of workers and/or the public to tritium and/or neutronically activated products. The key to controlling these hazards is inventory minimization, segregation and confinement. Recent technology developments in the area of tritium processing are key for minimization of inventories and optimizing the safety and environmental characteristics of future fusion facilities. In particular, development of efficient methods for tritium extraction from liquid lithium could have significant benefits beyond IFE (i.e., for application to a MFE liquid lithium divertor concept).

Initial safety studies indicate that hazards associated to the use of liquid lithium can be appropriately managed. Simulation of worst-case scenarios involving lithium spills with simultaneous air ingress and subsequent fire, indicate that the accident consequences are limited and that the potential release of radioactive material would remain below the limit for public evacuation. Nevertheless, potential exposure to lithium combustion products is an important chemical safety issue that needs assessment in the future. It is also recommended that future work continues to advance the design of the specialized equipment through experimental $R \& D$ in order to reduce existing technical uncertainties. The trade-offs between the tritium plant subsystems need to be carefully analyzed, and the design improved and optimized along the ALARA principle for tritium inventories, and the implementation of the confinement approach. Although the future licensing process for a commercial fusion facility is unclear at this stage, moving forward it will be important to develop or re-visit fusion safety guidelines so that they are as congruent as possible with updated regulations and with current understanding of fusion safety challenges.

\section{Acknowledgments}

This work was performed under the auspices of the U.S. Department of Energy by Lawrence Livermore National Laboratory under Contract DE-AC52-07NA27344.

\section{References}

[1] E. I. Moses, "The National Ignition Facility and the Promise of Inertial Fusion Energy," Fusion Science and Technology, 60 (2011) 11-16.

[2] National Nuclear Security Administration's Path Forward to Achieving Ignition in the Inertial Confinement Fusion Program, Report to Congress (2012).

[3] Committee on the Prospects for Inertial Confinement Fusion Energy Systems; Board on Physics and Astronomy; Board on Energy and Environmental Systems; Division on Engineering and Physical Sciences; National Research Council, An Assessment of the Prospects for Inertial Fusion Energy, ISBN-10: 0-30927081-2 (2013).

[4] M. Dunne, et al., "LIFE Pre-Conceptual Design Report," LLNL-AR-490773 (2011).

[5] M. Dunne, et al., "Timely Delivery of Laser Inertial Fusion Energy (LIFE)," Fusion Science and Technology, 60 (2011) 19-27.

[6] S. Reyes, et al., "LIFE: A Sustainable Solution for Developing Safe, Clean Fusion Power," Health Phys. 104(6): (2013) 641-7.

[7] T. Anklam et al., "The case for early commercialization of fusion energy," Fusion Science and Technology, 60 (2011) 66-71.

[8] S. Reyes, et al., "LIFE Tritium Processing: A Sustainable Solution for Closing the Fusion Fuel Cycle," Fusion Science and Technology, Vol. 64, N 2 (2013) 187-193.

[9] C. Day, I. Cristescu, B. Pégourié, B. Weyssow, "Considerations towards the Fuel Cycle of a steady-state DT Fusion Device," Proc. 23rd IAEA Fusion Energy Conference, Daejon, Republic of Korea, 2011.

[10] "The Tritium Plant for the Laser Inertial Fusion Engine (LIFE) Fuel Cycle," LANL-CP-11-01538/ 
SRNL-TR-2012-00036 Rev. 0., Los Alamos National Laboratory, Savannah River National Laboratory, and Savannah River Site Report (2011).

[11] Aspen Plus, User Models V7.2, Aspen Technology, Inc. (2010).

[12] L. K. Heung, H. T. Sessions, and X. Xiao, "TCAP hydrogen isotope separation using palladium and inverse columns," Fusion Science and Technology 60(4): (2011) 1331-1334.

[13] F. Gallucci, E. Fernandez, P. Corengia, and M. van Sint Annaland, "Recent advances on membranes and membrane reactors for hydrogen production." Chemical Engineering Science 92(0): (2013) 40-66.

[14] R. C. Duckworth, L. R. Baylor, S. J. Meitner, S. K. Combs, D. A. Rasmussen, M. Hechler, T. Edgemon, C. Barbier, R. Pearce, R. Kersevan, M. Dremel, and J.-C. Boissin, "Development and demonstration of a supercritical helium-cooled cryogenic viscous compressor prototype for the ITER vacuum system," AIP Conference Proceedings 1434(1) (2012) 1234-1242.

[15] LOS ALAMOS NATIONAL LABORATORY, "MCNP A General Monte Carlo N-Particle Transport Code," LAUR-03-1987, Los Alamos National Laboratory (2003).

[16] J. Sanz,. ACAB: inventory code for nuclear applications. User's manual v2008, NEA-1839 (2009).

[17] R. L. Klueh, and E. E. Bloom, "The development of ferritic steels for fast induced-radioactivity decay for fusion reactor applications," Nucl. Eng. Des. 2 (1985) 383-389.

[18] K. A. McCarthy, G. R. Smolik, S. L. Harms,"A Summary and Assessment of Oxidation Driven Volatility Experiments at the INEL and Their Application to Fusion Reactor Safety Assessments," INEL report EGG-FSP1193 (1994).

[19] D. W. Jeppson et al., "Lithium literature review: Lithium's properties and interactions," Hanford Engineering Development Laboratory Report HEDLTME-78-15 UC-20 (1978).

[20] M. M. Markowitz, "Alcali metal-water reactions," Journal of Chemical Education, Vol. 40, No. 12 (1963).

[21] R.E. Buxbaum, "The use of zirconium-palladium windows for the separation of tritium from the liquid metal breeder-blanket of a fusion reactor," Sep. Sci. Technol. 18 (1983) 1251.

[22] S. Tanaka, et al., "Hydrogen permeation through niobium membrane contacting with liquid lithium," J. Nucl. Mater. 97 (1981) 59.

[23] D.W. Rudd, et al., "The permeability of niobium to hydrogen," J. Phys. Chem., 66 (1962) 351.

[24] S.D. Clinton et al., "Recent experimental studies related to controlled thermonuclear reactors," Proc. Int. Conf. Radiation Effects and Tritium Technology for Fusion Reactors, October 1-3, Gatlinburg Tennessee, CONF750989, p. III.519 (1975).

[25] S.D. Clinton and J.S. Watson, "Tritium removal from liquid metals by absorption on yttrium," in Proc. 7th Symp. on Engineering Problems of Fusion Research, Knoxville, TN, October 25-28 (1977) 1647-1649.

[26] C.H. Wu, P. Hopkins, J. Reimann, H.R. Ihle, P. Din- ner, L. Barleon, S. Dorner, H. Feuerstein, D. Leger and V. Violente, "Tritium separation from liquid lithium," Draft Report on Urgent ITER Action No. 3, Garching (1993).

[27] D.K. Sze, R.F. Mattas, J. Anderson, R. Haange, H. Yoshida and O. Kveton, "Tritium recovery from lithium based on cold trap," presented at the ISFNT-3, Los Angeles (1994).

[28] D.K. Sze, T.Q. Hua, M.A. Dagher, L.M. Waganer, and M.A. Abdou, "Tritium processing system for the ITER
Li/V Blaket Test Module," Fusion Eng. and Des. 39-40 (1998) 859-864.

[29] H.R. Ihle and C.H. Wu, "Experimental determination of the partial pressures of D2, LiD and Li2D in equilibrium with dilute solutions of deuterium in liquid lithium," Proc. 8th Symp. on Fusion Technology, Nordwijker- hout; Netherlands, EUR 5182e (1974) 787-799.

[30] H.R. Ihle and C.H. Wu, "Recent experimental results on solutions of deuterium in lithium," in Proc. Int. Conf. Radiation Effects and Tritium Technology for Fusion Reactors, CONF-750989 (1976) IV-I-1l.

[31] H.R. Ihle and C.H. Wu, "The solubility of deuterium in, and its separation from liquid lithium by distillation," in Proc. 2nd Int. Congress on Hydrogen in Metals, Paris, ID8, 1, June 6-11 (1977) 1-8.

[32] H.R. Ihle and C.H. Wu, "Kinetic studies of solutions of deuterium in lithium by mass spectrometry," in Proc. 9th Symp. on Fusion Technology, Garmisch-Partenkirchen, Germany, EUR 5602 (1976) 329-335.

[33] V.A. Maroni, R.D. Wolson and G.G. Staahl, "Some preliminary considerations of a molten salt extraction process to remove tritium from liquid lithium fusion reactor blankets," Nucl. Technol. 25 (1975) 83.

[34] W.F. Calaway, "Electrochemical extraction of hydrogen from molten $\mathrm{LiF}-\mathrm{LiC} 1-\mathrm{LiBr}$ and its application to liquid lithium fusion reactor blanket processing," Nucl. Technol. 39 (1978) 63.

[35] Y. Asaoka, H. Moriyama and Y. Ito, "Equilibrium distributions of tritium in liquid lithium/molten salt systems," J. Nucl. Mater. 179-181 (1991) 879.

[36] H. Moriyama, Y. Asaoka and Y. Ito, "Kinetics of tritium recovery from liquid lithium by molten salt extraction," Nucl. Technol. 19 (1991) 1046.

[37] H. Moriyama, T. Nagae and Y. Ito, "Solubility of molten salt into liquid lithium,” J. Nucl. Mater. 211 (1994) 231.

[38] D.K. Sze, P.A. Finn, J. Bartlit, S. Tanaka, T. Teral and M. Yamawaki, "Combined gettering and molten salt process for tritium recovery from lithium," Fusion Eng. Des. 8 (1989) 339.

[39] S. Reyes, et al., "Updated Modeling of Postulated Accident Scenarios in ITER," Fusion Science and Technology, Vol. 56, No 2 (2009) 789-793.

[40] B. J. Merrill, " A lithium-air reaction model for the MELCOR code for analyzing lithium fires in fusion reactors," 7th IAEA Technical Committee Meeting on Fusion Power Plant Safety, Cannes, France, 13-16 June 2000, Fusion Eng. and Design, 54, 3-4 (2001) 485-93.

[41] M. Havstad, et al., "Revised initial release calculations," internal LLNL report (2013).

[42] S. Reyes, J. F. Latkowski, J. Sanz, J. Gomez del Rio, "Safety Assessment for Inertial Fusion Energy Power Plants: Methodology and Application to the Analysis of the HYLIFE-II and SOMBRERO Conceptual Designs," Journal of Fusion Energy Vol. 20 (1): (2001) 23-44.

[43] D. Chanin, M. L. Young, "Code Manual for MACCS2, User's Guide,” NUREG/CR-6613, Vol. 1, SAND97-0594 (1998).

[44] "Safety of Magnetic Fusion Facilities - Requirements," DOE-STD-6002-96, U. S. Department of Energy, Washington, D. C. (1996).

[45] "Safety of Magnetic Fusion Facilities - Guidance," DOESTD-6003-96, U. S. Department of Energy, Washington, D. C. (1996).

[46] N. Taylor, P. Cortes, "Lessons learnt from ITER safety \& licensing for DEMO and future nuclear fusion facilities," Fusion Eng. and Design, Vol. 89, 9-10 (2014) 19952000. 
[47] N. Taylor et al. "Preliminary safety analysis of ITER," Fusion Science and Technology, Vol. 56, 2 (2009) 573580.

[48] S. Reyes, J. F. Latkowski, J. Sanz, J. Gomez Del Rio, "Safety Assessment for Inertial Fusion Energy Power Plants: Methodology and Application to the Analysis of the HYLIFE-II and SOMBRERO Conceptual Designs," Journal of Fusion Energy Vol. 20 (1): (2001) 23-44. 